\title{
Public Health Intervention for Smoking Cessation
}

\author{
Soo Young Kim* \\ Department of Family Medicine, Kangdong Sacred Heart Hospital, College of Medicine, Hallym University, Seoul, Korea
}

\section{See original paper on 369}

Because quitting smoking is a very difficult task to achieve, a variety of interventions must be applied for smoking cessation.

Smoking cessation interventions can be divided into clinical and public health interventions. According to the socioecological model, public health interventions can be divided into individual, interpersonal, and community categories. ${ }^{1)}$ Among the smoking cessation or other health promotion domain interventions published in the Korean Journal of Family Medicine, inpatient management is a representative individual intervention, ${ }^{2,3)}$ peer support is a representative interpersonal intervention, ${ }^{4}$ and pricing policy is a representative community intervention. ${ }^{5)}$

In the present issue, Khafagy et al. ${ }^{6}$ investigated the effect of patient empowerment versus health education on the nicotine dependence score and progress of patients under different stages of smoking cessation, This study selected 76 smokers attending family medicine clinics, who were allocated into two groups: empowerment and health education groups, finding that the number of participants from the empowerment group who progressed from pre-intervention to post-intervention was significantly higher than in the health education group $(\mathrm{P}=0.04)$. There was a significant improvement in the stage of change of patients under the empowerment model, although there was no statistically significant difference between the groups in the number of participants who stopped smoking.

In light of these results, it can be said that both the empowerment model and traditional health education have similar positive effects on decreasing the nicotine dependence level. The patient empowerment model, a representative individual intervention, is a combination of counseling and motivation. It is difficult to say that it is clearly more effective than traditional education, but it is undoubtedly one of the many interventions that can be provided for smoking cessation.

Smoking cessation is a health promotion area that is very difficult to achieve; therefore, a combination of several interventions should be used to maximize the effect.

In this regard, the patient empowerment model has the potential to emerge as a testable tool, although it has the disadvantage of not being easy to implement.

\section{CONFLICT OF INTEREST}

No potential conflict of interest relevant to this article was reported.

\section{ORCID}

Soo Young Kim: https://orcid.org/0000-0002-3205-9408

\section{REFERENCES}

1. Sorensen G, Barbeau E, Hunt MK, Emmons K. Reducing social disparities in tobacco use: a social-contextual model for reducing tobacco use among blue-collar workers. Am J Public Health 2004;94:230-9.

2. Shin GH, Yi SW, Cheong YS, Park EW, Choi EY. Compliance and effectiveness of smoking cessation program started on hospitalized patients. Korean J Fam Med 2016;37:149-55.

3. Ha E, Jo JY, Ahn AL, Oh EJ, Choi JK, Cho DY, et al. Predictors of successful smoking cessation after inpatient intervention for stroke patients. Korean J Fam Med 2016;37:85-90.

4. Rajai N, Lami B, Pishgooie AH, Habibi H, Alavizerang F. Evaluating the effect of peer-assisted education on the function- 
ing in family caregivers of patients with schizophrenia: a clinical trial study. Korean J Fam Med 2021;42:356-62.

5. Kwon J, Kim H, Kim H, Yoo S, Park SG. Effect of increasing tobacco prices on stages of smoking cessation: a Korean nationwide data anal- ysis. Korean J Fam Med 2021;42:17-23.

6. Khafagy GM, Mahmoud MM, Soliman SS. Effect of patient empowerment model on smoking cessation: randomized controlled trial. Korean J Fam Med 2021;42:369-75. 